INTERNATIONAL JOURNAL OF MULTIDISCIPLINARY RESEARCH AND ANALYSis

ISSN(print): 2643-9840, ISSN(online): 2643-9875

Volume 04 Issue 09 September 2021

DOI: 10.47191/ijmra/v4-i9-13, Impact Factor: 6.072

Page No.- 1282-1285

\title{
The Comparison of Students' Motivation between Participation in Formal Education and In Music Activities
}

\section{Norawit Titicharoenrak}

Harrow International School Bangkok

ABSTRACT: This study compares different types of regulation that motivate school students to participate in their formal education and in music entertainment. The framework of self-determination is used in this study to convey various forms of regulation that play important roles in driving students to take action in both settings. A survey result based on 207 student respondents in Thailand revealed that although it is not uncommon to anticipate that there could be a variety of reasons for establishing this educational participation, ranging from extrinsic controls to intrinsic values, the students were more likely to be extrinsically and personally pressured in their formal study, compared to participating in music. On the other hand, they were prone to be more intrinsically driven when joining in music activities than studying.

\section{INTRODUCTION}

Many high school students in many countries, particularly Thailand, aspire to be artists, singers, and musicians in the music industry. This educational objective was established for a variety of reasons, ranging from financial security to the intrinsic value of personal fulfillment. However, while interest in music is increasing, research has shown that students feel pressured in their formal education and study of academic subjects, especially with online learning at this present time (Muilenburg \& Berge, 2005).

Psychologists have discovered that different types of motivation produce different outcomes in terms of learning and pleasure in learning (Williams et al., 1999). As shown in Figure 1, motivation can be classified into three types: amotivation, extrinsic motivation, and intrinsic motivation (Vallerand, et al, 1992). First, amotivation refers to a lack of motivation to complete a particular task. Such motivation encourages students to stay away from school. On the other hand, positive control is believed to be sustained by intrinsic motivation, in which a person acts just for the sake of enjoyment and interest, without setting an external goal in place (Lin et al., 2003). There is a clear association between this type of motivation and academic success, a greater sense of fulfillment, and perseverance, among other things (Gottfried, 1985; Gottfried, 1990). As a result, educators and teachers are increasingly concerned about how to encourage students' intrinsic desire in the classroom. Learning outcomes are likely to be better for learners who are intrinsically motivated, as opposed to those who aren't (Hein et al., 2004). Other types of incentive such as money, family expectations and grades are extrinsic in nature and are used to motivate people to take action. However, it has been demonstrated to have a negative impact on education (Lin et al., 2003). Research reveals that extrinsic incentive leads to lower academic performance, a lack of enthusiasm to learn, increased dropout rates, and unhappy mental states (Cabus \& De Witte, 2016).

Taking extrinsic motivation into account, the theory of self-determination divides it into four categories: external, introjected, identified, and integrated regulations (Deci \& Ryan, 2012). First, external regulations exist when one acts in response to external triggers such as money, grades, respect, rewards, praise, and so on. As a result, these tend to detach from one's own interests. It has a strong influence as a temptation. Second, introjected regulations concern personal guilts that arise when a specific action is withdrawn. Further, a person chooses to do something because of concern for their parents, close friends, teachers and other family members if the action is missed. Simply said, the feelings and expectations of others influence one's decision to carry out specific responsibilities. Third, when one is motivated by identified regulations, he or she recognizes the significance of an action and evaluates it as worthwhile, leading him or her to engage in it. Finally, when the value of a task is closely aligned with one's personal identity, life goals, and determination, one is thought to be motivated by integrated regulations (Markland et al., 2005). 


\section{The Comparison of Students' Motivation between Participation in Formal Education and In Music Activities}

\begin{tabular}{|l|c|c|c|c|c|}
\hline \multirow{2}{*}{ Amotivation } & \multicolumn{4}{|c|}{ Extrinsic motivation } & \multirow{2}{*}{$\begin{array}{c}\text { Intrinsic } \\
\text { motivation }\end{array}$} \\
\cline { 2 - 5 } & $\begin{array}{c}\text { External } \\
\text { regulation }\end{array}$ & $\begin{array}{c}\text { Introjected } \\
\text { regulation }\end{array}$ & $\begin{array}{c}\text { Identified } \\
\text { regulation }\end{array}$ & $\begin{array}{c}\text { Integrated } \\
\text { regulation }\end{array}$ & \\
\hline \multicolumn{5}{|c|}{ Internationalisation } \\
\hline
\end{tabular}

Figure 1: Types of motivation according to Self-Determination Theory

According to recent educational research, internal controls consisting of identified regulation, integrated regulation, and intrinsic motivation produce more positive learning outcomes (Deci \& Ryan, 2012). As a result, it is critical to assist students in recognizing the significance of their studies and how they can help them achieve their life goals. Furthermore, it is critical to help learners understand who they are and what they are intrinsically interested in, as these will help them find enjoyment in their education. This study is therefore being conducted to investigate various forms of motivation that drive high school students to participate in music in general, and singing in particular, according to the self-determination theory. Furthermore, it seeks to determine which types of motivation are potentially beneficial for making such a decision.

\section{METHODOLOGY}

A questionnaire was created that included six statements that represented amotivation, external regulation, introjected regulation, identified regulation, integrated regulation, and intrinsic motivation. It was distributed anonymously as an online survey to school respondents in Thailand. There were 207 responses in total retrieved from the data collection. In the questionnaire, the respondents were asked to rate their level of agreement in two different scenarios: one with their formal study at school and the other with their enjoyment of music. The influence of the six types of regulation on students was represented as mean scores from 5-Likert scaling responses ranging from strong disagreement to strong agreement. The comparison of the mean scores was analysed using a paired t-test at the significance level of $95 \%$.

\section{RESULTS}

In Table 1, the comparative results of self-determination levels between formal study and music are shown. Five critical issues emerge from the findings. First of all, although the respondents seem to disagree with amotivation in both settings, the mean score of formal study is statistically greater than that of music, at the significance level of $95 \%$, meaning that they are likely to find no motivation to study than to participate in music. Furthermore, when considering external regulation, another alarming warning appears. This is because the respondents are likely to be extrinsically driven to study, compared to participating in music, as the mean of the former is statistically greater than the latter, at the significance level of $95 \%$.

Table 1: Comparison of the level of self-determination between formal study and music

\begin{tabular}{|l|l|l|l|}
\hline & Study & Music & P-value \\
\hline Amotivation & 2.32 & 1.98 & 0.00 \\
\hline External regulation & 3.84 & 2.19 & 0.00 \\
\hline Introjected regulation & 3.49 & 2.13 & 0.00 \\
\hline Identified regulation & 3.19 & 1.98 & 0.00 \\
\hline Integrated regulation & 3.19 & 3.75 & 0.00 \\
\hline Intrinsic motivation & 3.11 & 3.88 & 0.00 \\
\hline
\end{tabular}

Third, with regard to introjected regulation, it is believed that the lower the mean score, the better the result. However, in the formal study setting, students are more likely to hold this form of regulation in a statistically greater level than in the setting of music participation. Turning to the remaining warning signs, both integrated regulation and intrinsic motivation show a similar 


\section{The Comparison of Students' Motivation between Participation in Formal Education and In Music Activities}

trend. Both of them are considered highly internalised which are beneficial from educational and psychological points of view. The findings reveal that both forms of motivation are statistically greater in the participation of music, compared to formal education. Finally, the only type of regulation that is pleasing in the formal study setting compared to its counterpart is identified regulation. The mean score is shown to be much higher and statistically significant.

\section{DISCUSSION}

This study points out concerns for educators, teachers, and parents that the school respondents found more positive in music participation than studying in a formal setting. Both regulations that seem to be less beneficial in education (i.e. extrinsic and introjected regulations and those that are more beneficial (i.e. integrated and intrinsic motivation) are more suitable in music participation. In other words, participating in music involves less external and personal pressures, while maintaining a greater level of internal satisfaction. Of course, music can be enjoyable. However, it is important for educators, teachers, and parents to be thinking about how to help their children to enjoy learning more. The only positive result in this study is the mean score from identified regulation. However, it is not surprising because this form of regulation is about the future of their education. The participants may realise that at least education will help them find a good job in the future. This is why the mean score of this form is greater in study.

When considering formal education, various forms of motivation can exist (Baker, 2004). According to self-determination theory, there are at least six types of motivation that can lead to a critical decision. First and foremost, when it comes to furthering one's education as a goal, many people who have no particular interest in studying may be unmotivated to do so. This may force them to make decisions based on the opinions of others. Some may even choose their studies at random, without regard for their personal interests or the potential consequences. It is unrealistic to expect students to be intrinsically motivated by joy and mere interest in the subject in educational settings. Of course, external factors have an impact in various ways.

However, this study found that when students discover the purpose and significance of the profession they are interested in (identified regulation), they are more likely to be intrinsically motivated. Furthermore, if they know who they truly are, what they genuinely want to do, what their personality is, and so on, the external goal of becoming a doctor will be closely integrated with their own identity (integrated regulation), potentially leading to pleasure in learning. This is supported by the fact that there were positive correlations between these three types of motivation, particularly intrinsic motivation and integrated regulation, in this cohort.

As a result, it is strongly advised that parents and teachers assist their children in discovering the meaningful purpose and significance of their formal education. Meanwhile, it is critical to help students understand who they are and what they enjoy. The sooner they discover this hidden value, the easier the path to a satisfactory education will be. Allowing students to choose their formal education based on parental expectations, social influences, and financial incentives is not regarded as beneficial. Instead of looking outward, they need to look inward and seek to understand and know who they are in order to move in the direction that will make them the best version of themselves.

\section{CONCLUSION}

This study contrasts various types of regulation that encourage school students to participate in formal education and music entertainment. In this study, the framework of self-determination is used to convey various forms of regulation that play important roles in motivating students to act in both settings. Self-determination theory presents types of regulation that drive one to take action, consisting of amotivation, extrinsic motivation (i.e. external, introjected, identified, and integrated regulations), and intrinsic motivation. A survey of 207 Thai students revealed that, while it is not uncommon to anticipate that there could be a variety of reasons for establishing this educational participation, ranging from extrinsic controls to intrinsic values, students were more likely to be extrinsically and personally pressured in their formal study. On the other hand, they were more likely to be intrinsically motivated when participating in music activities rather than studying. As a result, parents and teachers are strongly advised to assist their children in discovering the meaningful purpose and significance of their formal education. In the meantime, it is critical to assist students in understanding who they are and what they enjoy.

\section{REFERENCES}

1) Baker, S. R. (2004). Intrinsic, extrinsic, and a motivational orientations: Their role in university adjustment, stress, wellbeing, and subsequent academic performance. Current Psychology, 23(3), 189-202. 


\section{The Comparison of Students' Motivation between Participation in Formal Education and In Music Activities}

2) Cabus, S. J., \& De Witte, K. (2016). Why do students leave education early? Theory and evidence on high school dropout rates. Journal of Forecasting, 35(8), 690-702.

3) Deci, E. L., \& Ryan, R. M. (2012). Self-determination theory.

4) Gottfried, A. E. (1985). Academic intrinsic motivation in elementary and junior high school students. Journal of Educational Psychology, 77(6), 631.

5) Gottfried, A. E. (1990). Academic intrinsic motivation in young elementary school children. Journal of Educational Psychology, 82(3), 525.

6) Hein, V., Müür, M., \& Koka, A. (2004). Intention to be physically active after school graduation and its relationship to three types of intrinsic motivation. European Physical Education Review, 10(1), 5-19.

7) Lawler, E. E., \& Hall, D. T. (1970). Relationship of job characteristics to job involvement, satisfaction, and intrinsic motivation. Journal of Applied Psychology, 54(4), 305.

8) Lin, Y. G., McKeachie, W. J., \& Kim, Y. C. (2003). College student intrinsic and/or extrinsic motivation and learning. Learning and individual differences, 13(3), 251-258.

9) Markland, D., Ryan, R. M., Tobin, V. J., \& Rollnick, S. (2005). Motivational interviewing and self-determination theory. Journal of Social and Clinical Psychology, 24(6), 811-831.

10) Muilenburg, L. Y., \& Berge, Z. L. (2005). Student barriers to online learning: A factor analytic study. Distance education, 26(1), 29-48.

11) Vallerand, R. J., Pelletier, L. G., Blais, M. R., Briere, N. M., Senecal, C., \& Vallieres, E. F. (1992). The Academic Motivation Scale: A measure of intrinsic, extrinsic, and amotivation in education. Educational and Psychological Measurement, 52(4), 1003-1017.

12) Williams, G. C., Saizow, R. B., \& Ryan, R. M. (1999). The Importance of Self-determination Theory for. Academic Medicine, 74992, 995. 